\title{
Nutrient regulation of intestinal proliferation and apoptosis
}

\author{
J. C. Mathers \\ Human Nutrition Research Centre, Department of Biological and Nutritional Sciences, \\ University of Newcastle, Newcastle upon Tyne NEI 7RU, UK
}

The intestinal mucosa is an important interface between the animal and its environment. Through this interface the animal acquires water, nutrients and other bioactive compounds, whilst the mucosa provides a barrier against toxins and infective agents. The intestinal epithelium is replaced every $2-6 d$ (depending on species and intestinal site) and its integrity depends on the production of new cells at a rate equal to that at which cells are lost from the villus tip by extrusion (Madara, 1990) or by programmed cell death (apoptosis; Hall et al. 1994). Each villus is clothed by a single layer of epithelial cells which migrate up from six to ten surrounding crypts. Within the crypts, stem cells located at or near the bottom constitute a selfmaintaining population which, by asymmetric division, give rise to a new stem cell and to another daughter or 'transit' cell which, in turn, is capable of a limited number (perhaps four to five) of further divisions (Potten \& Loeffler, 1990). The stem (and transit) cells are pluripotent, giving rise to all four lineages, including Paneth cells, goblet cells, entero-endocrine cells and columnar absorptive cells (enterocytes). Growth of the intestine during early postnatal ontogenesis requires an increase in the number of crypts, which occurs by crypt fission (Cheng \& Bjerknes, 1985). Crypt fission rate post-weaning, which is normally at a relatively low level, can be increased by irradiation (Cairnie \& Millen, 1975), small-bowel resection (Totafurno et al. 1987) and treatment with mutagens (Park et al. 1995), but little is known about the effects of nutritional manipulation.

\section{Regulation of cell proliferation and apoptosis in the intestine}
Role of tumour suppressor gene APC in cell proliferation and apoptosis

The accessibility and distinctive tissue architecture of the gut mucosa and the accumulating knowledge of gene defects associated with colo-rectal tumourigenesis (Reale \& Fearon, 1996) have helped elucidate the roles of key genes regulating cell number in this epithelium. The tumour suppressor gene $A P C$ is normally expressed by non-dividing cells in the upper part of the crypt and on the villus. This, together with the upwards shift in distribution of dividing cells within crypts from individuals with familial adenomatous polyposis in whom one APC allele is mutated (Mills et al. 1995), led to the suggestion that the $A P C$ gene product suppressed cell proliferation. Direct evidence was published by Baeg et al. (1995), who showed that over-expression of APC blocked cell cycle progression from $G_{0}$ or $G_{1}$ to $S$ phase and was associated with reduced cyclin-dependent protein kinase 2 activity. The APC protein is large (2843 amino acid residues), with several distinct domains, is located in the cell cytoplasm and probably functions normally as an homo-oligomer. Whilst its cellular role(s) is not fully understood, it seems likely that APC acts as a switch or gate-keeper, receiving extracellular signals via E-cadherin and $\beta$-catenin and modulating these before onward transmission via the actin cytoskeleton. Transfection of full length $A P C$ into HT-29 colo-rectal cancer cells (in which both $A P C$ alleles are mutated) resulted in considerable diminution of cell growth and several-fold increase in apoptosis (assayed by Hoechst staining of floating cells; Morin et al. 1996). How APC switches on apoptosis is not known, but it is now apparent that APC plays a key role in regulating both proliferation and apoptosis, thereby regulating cell number in the intestine. Recent reports of the absence of any difference in cell proliferation in the macroscopically-normal intestinal mucosa of mice engineered to have a mutation in one of the Apc alleles compared with the wild-type controls (Wasan et al. 1997; Mathers et al. 1998) suggests that as little as $50 \%$ of the normal cell complement of the Apc protein may be sufficient to ensure normal regulation of proliferation.

\section{Apoptosis: roles of the bcl-2 family genes}

Kerr et al. (1972) coined the term 'apoptosis' to describe the 'active, inherently programmed' form of cell death which acts as the counter-weight to mitosis in the regulation of cell number in tissue homeostasis. It is activated during embryonic development, allowing the focal removal of unwanted cells, and during therapeutically-induced tumour regression. Apoptotic cells undergo a programme of 
morphological changes, including (often) separation from adjacent cells, cell shrinkage, chromatin condensation, nuclear fragmentation and the production of discrete membrane-bound apoptotic bodies which are phagocytosed by neighbouring cells without inducing an inflammatory response (Que \& Gores, 1996). Internucleosomal DNA cleavage occurs relatively late in the apoptotic pathway to produce mono- and oligomers of about 200 base pairs which yield characteristic ladders on agarose gel electrophoresis.

The proto-oncogene $b c l-2$ encodes a $26 \mathrm{kDa}$ membraneassociated protein which protects cells against apoptosis. The $b c l-2$ homologues $b c l-X_{L}$ and $M C L-1$ are also cell death suppressors, whilst other members of this family, including $B a x, B c l-X s, B a k$ and $B a d$, are cell death promoters. Competing dimerization by the protein products of this gene family is probably responsible for determining whether apoptosis is switched on or off (Lu et al. 1996). Homodimers of bcl-2 protect cells against apoptosis, while heterodimerization of bcl-2 and Bax switches on programmed cell death (Fig. 1). Kamada et al. (1995) provided strong evidence for the role of $b c l-2$ in maintaining intestinal mucosal integrity by generating mice lacking the $b c l$-2 gene using homologous recombination in embryonal stem cells. Homozygous $b c l$-2-deficient mice had short, bizarre-shaped intestinal villi with few mitotic cells and clusters of apoptotic cells.

Hall et al. (1994) reported observing apoptotic cells in the stomach, small-intestinal and colonic epithelium of rodents and human subjects. The numbers of apoptotic cells observed were small, but Hall et al. (1994) argued that this was as expected because apoptosis is a rapid process (apoptotic bodies may be cleared in 1-2 h). Their calculations suggested that apoptosis might account for the bulk of cell loss in the intestine and, thus, is a central feature of the regulation of cell number in adult tissues. This is a novel suggestion since it has been accepted wisdom that most cell loss from the intestine occurs by cell shedding or exfoliation from the villus tip (small intestine) or luminal surface (colon). In support of the conventional view, Madara (1990) developed an elegant model to explain how cellular extrusion could occur without loss of mucosal integrity. Resolution of this controversy would be assisted

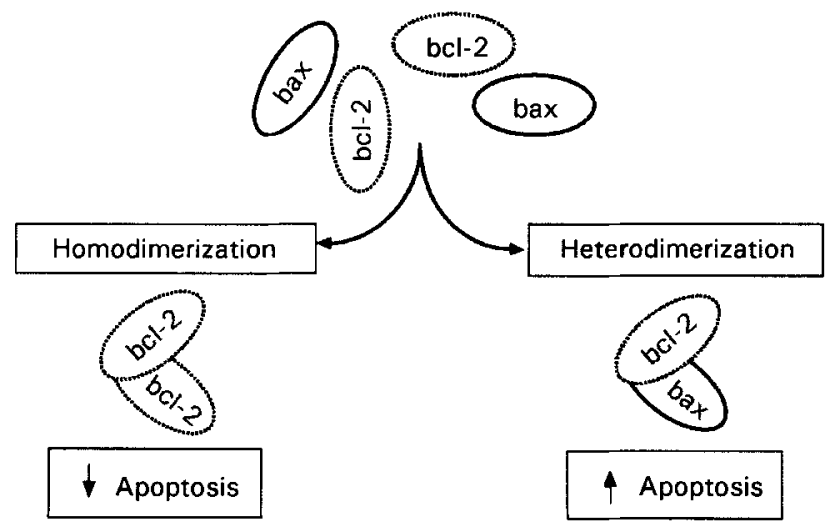

Fig. 1. Competing dimerization of bcl-2 family proteins determines whether apoptosis is switched off or switched on. by the development of more robust methods of quantifying apoptosis, especially if this included a measurement of rate as distinct from state (the analogy is with the stathmokinetic approach to the measurement of crypt cell proliferation rate; Goodlad \& Wright, 1982).

\section{Dietary modulation of cell proliferation and apoptosis}

Intestinal cell proliferation responds rapidly to changes in the amount and nature of the diet. Starvation of rats for $72 \mathrm{~h}$ reduced the number of mitotic cells per colonic crypt from 6.8 ( $\mathrm{SD} 0.2$ ) to 5.3 (SD 0.3), whilst after $24 \mathrm{~h}$ refeeding this had increased to 8.0 (SD 0.3) mitotic cells per crypt (Konishi et al. 1996). Massive small-bowel resection leads to hypertrophy of both the muscle layers and mucosa of the residual intestine. Not surprisingly, this is associated with a large, sustained (up to at least $7 \mathrm{~d}$ ) increase in crypt cell proliferation, and Helmrath et al. (1997) have reported recently that apoptotic index (no. of apoptotic cells per crypt secretion) was increased within $12 \mathrm{~h}$ of surgery with further increases up to day 3 . This high rate of apoptosis (about seven times that in the sham-operated controls) was maintained to day 7 post-surgery, presumably as a means of removing excess cells in the establishment of a new steady state. Excessive rates of epithelial apoptosis resulting from exposure to gluten in genetically-susceptible individuals appear to contribute to the villous atrophy, which results in a characteristically flat small-bowel mucosa despite a fourfold increase in crypt cell proliferation in active coeliac disease (Moss et al. 1996). Consumption of gluten-free diets returned small-intestinal apoptotic scores (no. of apoptotic cells per 100 total epithelial cells) to normal (Moss et al. 1996). Lewin \& Weinstein (1996) have suggested that apoptosis may be de-regulated in other intestinal disorders characterized by 'flat' lesions, e.g. those induced by chemotherapy or folate or vitamin $B_{12}$ deficiencies. Apoptosis may also be important in the normal maturation of the intestine after birth. Culture of human fetal small intestine with the exogenous nucleotide AMP resulted in suppression of cell proliferation, induction of differentiation and the appearance of apoptotic cells on the villi (Tanaka et al. 1996). This was accompanied by an increase in Bax mRNA but no change in $b c l-2$.

\section{Effects of NSP on intestinal cell proliferation}

It is well established that plant structural carbohydrates play an important role in the development of the rumen mucosa during weaning (Tamate et al. 1962). More recently, evidence has accumulated that certain dietary NSP increase cell proliferation in rodents (Jacobs \& Lupton, 1984; Goodlad et al. 1987; Mathers et al. 1993; Gee et al. 1996; Key et al. 1996). The reason for this hyperproliferation is not clear, and some possible factors are summarized in Fig. 2. Soluble NSP sources which increase gut lumen viscosity, e.g. guar gum, may result in delayed digestion and absorption, the transfer of nutrients to the distal intestine (as indicated by up-regulation of brush-border hydrolases in the terminal ileum; Mathers et al. 1992) and increased crypt cell proliferation (Pell et al. 


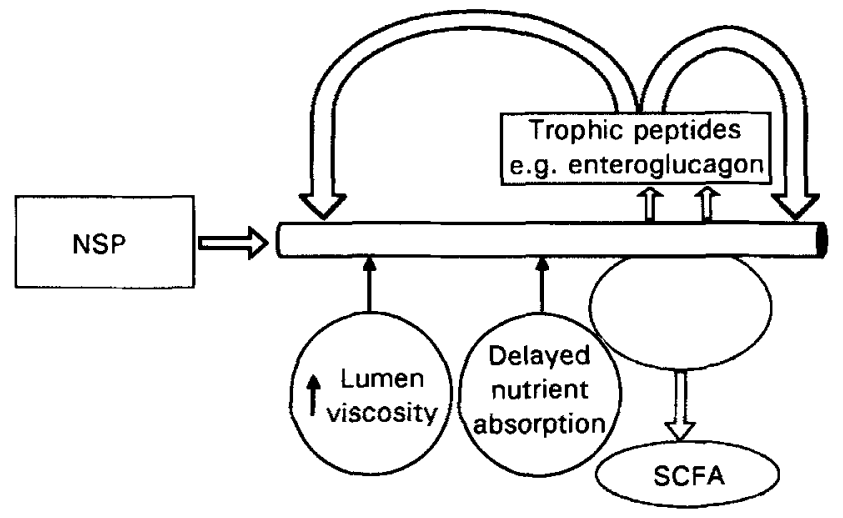

Fig. 2. Conceptual model of potential factors influencing crypt cell proliferation when NSP are consumed. SCFA, short-chain fatty acids.

1992). This may be mediated by the increased release of trophic peptides, e.g. enteroglucagon from the L-cells of the distal small bowel and colon (Goodlad et al. 1987). In addition, NSP are fermented in the caecum and colon, producing short-chain fatty acids (SCFA) which have been shown to be trophic for both the rumen epithelium (Sakata \& Tamate, 1978) and the rodent intestinal mucosa (Sakata, 1987).

We tested the hypothesis that lumen viscosity is an important factor modulating crypt cell proliferation by feeding rats semi-purified diets containing (as the only NSP source) cellulose (known to have no effect on lumen viscosity or cell proliferation) or guar-gum preparations of contrasting molecular mass and, therefore, viscosity (Lynn et al. 1994). With all guar-gum preparations, intestinal epithelial cell proliferation was increased throughout the small and large bowels, with greater increases for the more viscous products. Gee et al. (1996) showed that hydroxypropylmethylcellulose, which increases lumen viscosity but is not fermented, had no effect on crypt cell proliferation in the distal ileum. Similarly, there was no effect with the non-viscous disaccharide lactitol, which is not digested in the small bowel, but is rapidly fermented in the large bowel and which stimulated enteroglucagon release. Guar gum, which is also readily fermented, was the most potent stimulator of enteroglucagon release and the only one of the test carbohydrates to increase cell proliferation. This suggests that cell proliferation may be modulated by an interaction between lumen viscosity and SCFA production and that enteroglucagon alone is insufficient to cause a trophic effect (Gee et al. 1996).

\section{Short-chain fatty acids, cell proliferation and apoptosis}

Direct infusion of SCFA into the distal intestine of rats fed on elemental diets stimulated large-bowel epithelial proliferation rate (Sakata, 1987), whilst isolation of the large bowel from its normal ileal supply of substrate and, therefore, prevention of fermentation and SCFA production, suppressed proliferation (Sakata, 1988). Supplementation of parenteral nutrition with SCFA caused hypertrophy of the residual intestine following massive small-bowel resection (Koruda et al. 1988). This evidence supports the suggestion that SCFA are lumen trophic factors for the rodent intestine (Sakata, 1987) as they are for the rumen (Sakata \& Tamate, 1978).

Since most of the studies in this area have been carried out using models in which the basal level of SCFA production is suppressed, it could be argued that the additional SCFA merely return proliferative rates to normal, i.e. that this is an homeostatic response to a normal gut lumen metabolite (Fig. 3). We examined this possibility by feeding rats on diets based on white or wholemeal breads (similar to human 'Western' diets) which would be expected to provide normal background levels of SCFA production. These diets were supplemented with graded amounts of cooked haricot beans (Phaseolus vulgaris) which are good sources of fermentable carbohydrates (NSP, resistant starch and oligosaccharides) and resulted in several-fold increases in SCFA production, with the greatest increase for butyrate (Key et al. 1996). Despite the very large increases in SCFA, there was no evidence that this had any effect on duodenal cell proliferation. When the basal diet contained wholemeal bread there was no effect of enhanced SCFA supply on cell proliferation in the caecum or colon, but with the white bread-based diets, addition of haricot beans increased caecal cell proliferation. We concluded that evidence that SCFA are responsible for enhanced cell proliferation above normal levels is not convincing (Key et al. 1996). In those instances where enhanced SCFA supply is accompanied by increased cell proliferation, the increase may be:

(a) from a hypoproliferative state towards normal (Fig. 3);

(b) a transient phenomenon accompanying tissue hypertrophy; or

(c) an homeostatic response to increased cell loss by exfoliation or apoptosis.

Whilst SCFA (and especially butyrate) may be trophic for the intestinal mucosa in certain circumstances in vivo, butyrate is a potent inhibitor of DNA synthesis and cell proliferation in vitro and is associated with induction of cellular differentiation (Young \& Gibson, 1995). These

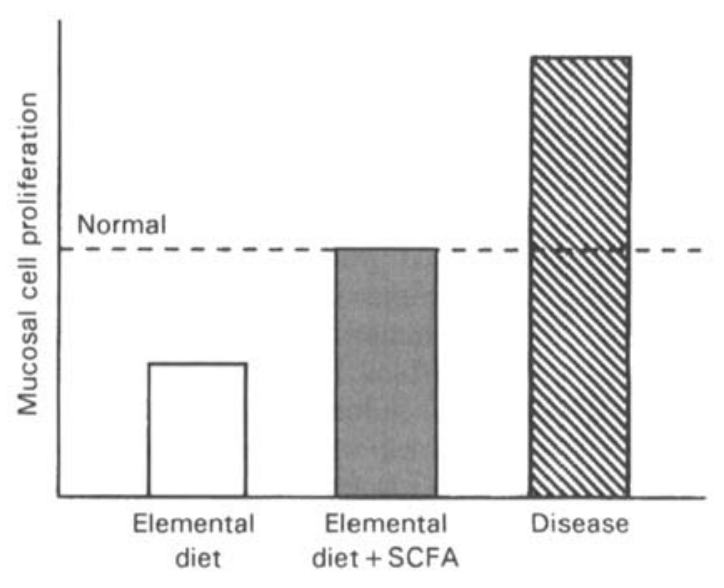

Fig. 3. Hypothesis: hypoproliferative mucosal epithelium in animals fed on elemental diets is returned towards normal by short-chain fatty acids (SCFA). There is no convincing evidence that extra SCFA production causes hyperproliferation characteristic of disease states. 
changes in gene expression may be a result of hyperacetylation of histones and enhanced methylation of DNA, but it is unlikely that these global modifications of chromatin proteins and chromatin structure can explain the effects of butyrate since this SCFA switches off and switches on expression of only a limited number of genes (Kruh et al. 1995): Incubation of adenoma and colo-rectal tumour cell lines with physiological concentrations of SCFA induced apoptosis, with butyrate being the most effective agent (Hague et al. 1995). In contrast, Hass et al. (1997) have reported recently that the absence of butyrate from the medium promoted apoptosis in guinea-pig proximal colonic mucosa incubated in Ussing chambers. This was associated with increased expression of $B a x$ but no change in $b c l-2$. In an accompanying editorial, Hague et al. (1997) have argued that since butyrate is a primary fuel for colonocytes in vivo (Roediger, 1982), rapid apoptosis after transfer into culture may be a result of energy deprivation despite the presence of glucose in the incubation solution.

\section{Implication for colo-rectal cancer risk}

Increased cell division may be an early event in the development of many human cancers because it increases the risk of accumulation of errors (mutations) in the newlyreplicated DNA (Preston-Martin et al. 1990). Greater numbers of mitotic cells or an upwards expansion of the proliferative zone within the crypts in macroscopicallynormal tissue is associated with greater risk of colo-rectal cancer (Mills et al. 1995; Wargovich, 1996). I have suggested previously that the changes in cell proliferation which accompany increased intake of NSP and other fermentable carbohydrates are likely to be physiological not pathological (Fig. 3). Rates of cell proliferation are much greater in the small-bowel mucosa than in the colon, yet tumours in the small intestine are very much rarer than in the large bowel. This might be explained on the basis that it is only mutations in the stem cells which matter since transit cells (Potten \& Loeffler, 1990) have a limited capacity for further division. Hickman et al. (1995) have argued that the site difference in cancer incidence may arise because apoptosis of stem cells is rare in the colon when compared with the small intestine. There may be 'insufficient altruistic apoptosis' in the colon (Hickman et al. 1995) in the face of a greater mutagenic load. If dietary modifications increased cell proliferation on a sustained basis, this might increase the risk of accumulation of mutations because of the greater number of mitotic events, but only if this increased proliferation was the result of a greater number of asymmetric divisions of stem cells as distinct from more symmetric divisions of transit cells. Because of the great difficulty in distinguishing stem cells from other dividing cells in the intestine (Potten \& Loeffler, 1990), it is not yet known where the primary increase in cell numbers arises in response to dietary manipulation. Finally, despite the evidence that butyrate may increase cell proliferation in vivo under certain conditions, it is unlikely that this has any adverse effect on colo-rectal cancer risk, since butyrate enemas afforded protection against large bowel cancer in a mutagen-treated rat model (D'Argenio et al. 1996).

\section{Acknowledgements}

This work is supported by a contract from the Ministry of Agriculture, Fisheries and Food (ANO317) and by grants from the Cancer Research Campaign and World Cancer Research Fund.

\section{References}

Baeg G-H, Matsumine A, Kuroda T, Bhattacharjee RN, Miyashiro I, Toyoshima K \& Akiyama T (1995) The tumour suppressor gene product APC blocks cell cycle progression from $\mathrm{G} 0 / \mathrm{G} 1$ to $S$ phase. EMBO Journal 14, 5618-5625.

Cairnie AB \& Millen BH (1975) Fission of crypts in the small intestine of the irradiated mouse. Cell and Tissue Kinetics $\mathbf{8}$, 189-196.

Cheng H \& Bjerknes M (1985) Whole population cell kinetics and postnatal development of the mouse intestinal epithelium. Anatomical Record 211, 420-426.

D'Argenio G, Cosenza V, Cave MD, Iovino P, Valle ND, Lombardi G \& Mazzacca G (1996) Butyrate enemas in experimental colitis and protection against large bowel cancer in a rat model. Gastroenterology 110, 1727-1734.

Gee IM, Lee-Finglas W, Wortley GM \& Johnson IT (1996) Fermentable carbohydrates elevate plasma enteroglucagon but high viscosity is also necessary to stimulate small bowel mucosal cell proliferation in rats. Journal of Nutrition 126, 373-379.

Goodlad RA, Lenton W, Ghatei MA, Adrian TE, Bloom SR \& Wright NA (1987) Effects of an elemental diet, inert bulk and different types of dietary fibre on the response of the intestinal epithelium to refeeding in the rat and relationship to plasma gastrin, enteroglucagon, and PYY concentrations. Gut 28,171180.

Goodlad RA \& Wright NA (1982) Quantitative studies on epithelial replacement in the gut. In Techniques in Life Sciences. Digestive Physiology, pp. 212/1-212/13 [DA Hitchen, editor]. Limerick, Republic of Ireland: Elsevier Scientific Publishers Ireland Ltd.

Hague A, Elder DJE, Hicks DJ \& Parakseva C (1995) Apoptosis in colorectal tumour cells: induction by the short chain fatty acids butyrate, propionate and acetate and by the bile salt deoxycholate. International Journal of Cancer 60, 400-406.

Hague A, Singh B \& Paraskeva C (1997) Butyrate acts as a survival factor for colonic epithelial cells: Further fuel for the in vivo versus in vitro debate. Gastroenterology 112, 1036-1040.

Hall PA, Coates PJ, Ansari B \& Hopwood D (1994) Regulation of cell number in the mammalian gastrointestinal tract: the importance of apoptosis. Journal of Cell Biology 107, 35693577.

Hass R, Busche R, Luciano L, Reale E \& van Englehardt W (1997) Lack of butyrate is associated with induction of Bax and subsequent apoptosis in the proximal colon of guinea pig. Gastroenterology 112, 875-881.

Helmrath MA, Erwin CR, Shin CE, Brown DL \& Warner BW (1997) Enterocyte apoptosis is increased following small bowel resection. Gastroenterology 112, A1447.

Hickman JA, Potten CS, Merritt AJ \& Fisher TC (1995) Apoptosis and cancer chemotherapy. In The Role of Apoptosis in Development, Tissue Homeostasis and Malignancy. Death from Inside Out, pp. 83-89 [TM Dexter, MC Raff and AH Wyllie, editors]. London: Chapman and Hall.

Jacobs LR \& Lupton JR (1984) Effects of dietary fibres on rat large bowel mucosal growth and cell proliferation. American Journal of Physiology 246, G378-G385. 
Kamada S, Shimono A, Shinto Y, Tsujimura T, Takahashi T, Noda T, Kitamura Y, Kondoh H \& Tsujimoto Y (1995) bcl-2 deficiency in mice leads to pleiotropic abnormalities: accelerated lymphoid cell death in thymus and spleen, polycystic kidney, hair hypopigmentation, and distorted small intestine. Cancer Research 55, 354-359.

Kerr JFR, Wyllie AH \& Currie AR (1972) Apoptosis: A basic biological phenomenon with wide-ranging implications in tissue kinetics. British Journal of Cancer 26, 239-257.

Key FB, McClean D \& Mathers JC (1996) Tissue hypertrophy and epithelial proliferation rate in the gut of rats fed on bread and haricot beans (Phaseolus vulgaris). British Journal of Nutrition 76, 273-286.

Konishi H, Steinbach G, Hittelman WN, Fujita K, Lee JJ, Glober GA, Levin B, Andreeff M, Goodacre AM \& Terry NHA (1996) Cell kinetic analysis of intact rat colonic crypts by confocal microscopy and immunofluorescence. Gastroenterology 111, $1493-1500$.

Koruda MJ, Rolandelli RH, Settle G, Zimmaro DM \& Rombeau JL (1988) Effect of parenteral nutrition supplemented with short chain fatty acids on adaptation to massive small bowel resection. Gastroenterology 95, 715-720.

Kruh J, Defer N \& Tichonicky L (1995) Effects of butyrate on cell proliferation and gene expression. In Physiological and Clinical Aspects of Short-chain Fatty Acids, pp. 275-288 [JH Cummings, JL Rombeau and T Sakata, editors]. Cambridge: Cambridge University Press.

Lewin D \& Weinstein WM (1996) Cell death - where is thy sting? Gut 39, 883-884.

Lynn ME, Mathers JC \& Parker DS (1994) Increasing luminal viscosity stimulates crypt-cell proliferation throughout the gut. Proceedings of the Nutrition Society 53, 226A.

Lu Q-L, Abel P, Foster CS \& Lalani E-N (1996) Bcl-2: Role in epithelial differentiation and oncogenesis. Human Pathology 27, 102-110.

Madara JL (1990) Maintenance of the macromolecular barrier at cell extrusion sites in intestinal epithelium: physiological rearrangement of tight junctions. Journal of Membrane Biology 116, $177-184$.

Mathers JC, Kennard J \& James OFW (1993) Gastrointestinal responses to oats consumption in young and elderly rats: digestion, large bowel fermentation and crypt cell proliferation. British Journal of Nutrition 70, 567-584.

Mathers JC, Kooshkghazi M, Coaker J, Williamson S, Kartheuser A, Burn J \& Fodde R (1998) Is crypt cell proliferation a reliable bio-marker of intestinal cancer risk? Proceedings of the Nutrition Society 57, 43A.

Mathers JC, Lawlor PA \& Parker DS (1992) Effects of guar gum supplementation of breakfast cereals on small intestinal hydrolases in the rat. Proceedings of the Nutrition Society 51, $2 \mathrm{~A}$.

Mills SJ, Shepherd NA, Hall PA, Hastings A, Mathers JC \& Gunn A (1995) Proliferative compartment deregulation in the nonneoplastic colonic epithelium of familial adenomatous polyposis. Gut 36, 391-394.

Morin PJ, Vogelstein B \& Kinzler KW (1996) Apoptosis and APC in colorectal tumorigenesis. Proceedings of the National Academy of Sciences USA 93, 7950-7954.
Moss SF, Attia L, Scholes JV, Walters JRF \& Holt PR (1996) Increased small intestinal apoptosis in coeliac disease. Gut 39, 811-817.

Park H-S, Goodlad RA \& Wright NA (1995) Crypt fission in the small intestine and colon. A mechanism for the emergence of G6PD locus-mutated crypts after treatment with mutagens. American Journal of Pathology 147, 1416-1427.

Pell JD, Gee JM, Wortley GM \& Johnson IT (1992) Dietary com oil and guar gum stimulate intestinal crypt cell proliferation by independent but potentially synergistic mechanisms. Journal of Nutrition 122, 2447-2456.

Potten CS \& Loeffler M (1990) Stem cells: attributes, cycles, spirals, pitfalls and uncertainties. Lessons for and from the Crypt. Development 110, 1001-1020.

Preston-Martin S, Pike MC, Ross RK, Jones PA \& Henderson BE (1990) Increased cell division as a cause of human cancer. Cancer Research 50, 7415-7421.

Que FG \& Gores GJ (1996) Cell death by apoptosis: basic concepts and disease relevance for the gastroenterologist. Gastroenterology 110, 1238-1243.

Reale MA \& Fearon ER (1996) Gene defects in colorectal tumorigenesis. In Prevention and Early Detection of Colorectal Cancer, pp. 63-86 [GP Young, P Rozen and B Levin, editors]. London: W.B. Saunders \& Co. Ltd

Roediger WEW (1982) Utilization of nutrients by isolated epithelial cells of the rat colon. Gastroenterology 83, 424-429.

Sakata T (1987) Stimulatory effect of short-chain fatty acids on epithelial cell proliferation in the rat intestine: a possible explanation for the trophic effects of fermentable fibre, gut microbes and luminal trophic factors. British Joumal of Nutrition 58, 95-103.

Sakata T (1988) Depression of intestinal epithelial cell production rate by hindgut bypass in rats. Scandinavian Journal of Gastroenterology 23, 1200-1202.

Sakata T \& Tamate H (1978) Ruminal epithelial cell proliferation accelerated by rapid increase in intraruminal butyrate. Joumal of Dairy Science 61, 1109-1113.

Tamate H, McGilliard AD, Jacobson NL \& Getty R (1962) Effects of various dietaries on the anatomical development of the stomach in the calf. Journal of Dairy Science 45, 408-420.

Tanaka M, Lee K, Martinez-Augustin O, He Y, Sanderson IR \& Walker WA (1996) Exogenous nucleotides alter proliferation, differentiation and apoptosis of human small intestinal epithelium. Journal of Nutrition 126, 424-433.

Totafurno J, Bjerknes M \& Cheng H (1987) The crypt cycle. Crypt and villus production in the adult intestinal epithelium. Biophysics Journal 52, 279-294.

Wargovich MJ (1996) Precancer markers and prediction of tumorigenesis. In Prevention and Early Detection of Colorectal Cancer, pp. 89-101 [GP Young, P Rozen and B Levin, editors]. London: W.B. Saunders \& Co. Ltd

Wasan HS, Park HS, Lui KC, Mandir N, Winnett A, Sasieni P, Bodmer WF, Goodlad RA \& Wright NA (1997) APC in the regulation of intestinal crypt fission. Gastroenterology 112, A667.

Young GP \& Gibson PR (1995) Butyrate and the human cancer cell. In Physiological and Clinical Aspects of Short-chain Fatty Acids, pp. 319-335 [JH Cummings, JL Rombeau and T Sakata, editors]. Cambridge: Cambridge University Press. 